\title{
The effect of HMGB1 and RAGE on the clinicopathological and prognostic features of prostate cancer
}

\author{
Dao-Jun Lv \\ Guangdong Key Laboratory of Urology, Department of Urology, Minimally Invasive Surgery Center, The First Affiliated Hospital \\ of Guangzhou Medical University, Guangzhou 510230, Guangdong, China.
}

Correspondence to: Prof. Dao-Jun Lv, Department of Urology, Minimally Invasive Surgery Center, The First Affiliated Hospital of Guangzhou Medical University, Kangda Road 1\#, Haizhu District, Guangzhou 510230, Guangdong, China. E-mail: daojunlv88@gzhmu.edu.cn

How to cite this article: Lv DJ. The effect of HMGB1 and RAGE on the clinicopathological and prognostic features of prostate cancer. J Trans/ Genet Genom 2021;5:414-22. https://dx.doi.org/10.20517/jtgg.2021.34

Received: 7 Jul 2021 First Decision: 16 Aug 2021 Revised: 6 Sep 2021 Accepted: 9 Sep 2021 Published: 5 Nov 2021

Academic Editor: Sanjay Gupta Copy Editor: Yue-Yue Zhang Production Editor: Yue-Yue Zhang

\begin{abstract}
As a DNA-binding protein, high mobility group box 1 (HMGB1) has been shown be involved in various biological activities, including transcription regulation, DNA repair, genomic stability, and extracellular signaling. Accumulating evidence indicates that HMGB1 has an important role in biological processes in cancer. Moreover, HMGB1 has been shown to have intracellular and extracellular roles, activating key cancerogenic signaling pathways. The main signal pathway is activated via the interaction of HMGB1 with its receptor, receptor for advanced glycation end-products (RAGE). In addition, overexpression of HMGB1/RAGE occurs in certain types of primary tumors and has been linked to increased metastasis and poorer prognosis. In our previous research, we demonstrated that co-expression of HMGB1 and RAGE is associated with cancer progression and poor patient outcome in prostate cancer ( $\mathrm{PCa}$ ). Together with the recent published evidence, we describe and speculate on the character of the HMGB1/RAGE axis in PCa progression and elaborate on future prospects for the application of potential strategies to target HMGB1 in PCa therapy.
\end{abstract}

Keywords: High mobility group box 1, receptor for advanced glycation end-products, prostate cancer 


\section{INTRODUCTION}

Prostate cancer $(\mathrm{PCa})$ is one of the most frequent human malignancies and is the second leading cause of death by cancer in the western male population ${ }^{[1]}$. Currently, prostate-specific antigen (PSA) is a significant marker for diagnosing PCa. Nevertheless, the accuracy and specificity of PSA for predicting PCa are not high enough ${ }^{[2]}$. Therefore, it is urgent to identify more effective diagnostic hallmarks and therapeutic targets for PCa.

The high mobility group box 1 (HMGB1) protein is a ubiquitous non-histone component of chromatin that is involved in DNA replication and DNA repair process ${ }^{[3-6]}$. It has two main functions depending on the cellular localization, post-translational modification. and context of the cell. In the cell nucleus, HMGB1 functions as a DNA-binding complex to sustain nucleosome structure without sequence specificity and aids in distorting the DNA structure to allow access for repair and transcription protein $\mathrm{s}^{[7,8]}$. The interactions of HMGB1 with various transcription factors, such as NF-kB members ${ }^{[9]}$, $\mathrm{p}^{2} 3^{[10]}$, and TATA-binding $\operatorname{protein}^{[11]}$, can promote or suppress transcription depending on the cellular context. Owing to its ability to bind distorted/damaged DNA structures, HMGB1 has been reported to be involved in four DNA repair pathways: nucleotide excision repair, base excision repair, mismatch repair, and DNA double-strand break repair $^{[12]}$.

Interestingly, HMGB1 not only promotes DNA damage recognition but can also increase DNA repair efficiency through direct interactions with DNA repair enzymes ${ }^{[13]}$. Besides, HMGB1 can also be subjected to posttranslational modification, which modulates interactions of the proteins with DNA/chromatin and regulates their nuclear translocation and secretion ${ }^{[6,14]}$. Accumulating evidence indicates that the role of HMGB1 extends beyond the nucleus, notably its extracellular role in inflammation ${ }^{[15]}$. Outside the cell, it can be passively secreted from dying or stressed cells or actively secreted from immune cells, such as activated macrophages, which can function as a danger signal and proinflammatory mediator through interaction with multiple other molecules, including RNA, proteins, lipopolysaccharides, nucleosomes, and several cell surface receptors [e.g., receptor for advanced glycation end product (RAGE), toll-like receptor (TLR) 2, and TLR 4], with RAGE being regarded as a dominant receptor for HMGB1 in tumorigenesis ${ }^{[5,16]}$. Extracellular HMGB1/RAGE interactions facilitate tumor proliferation via activation of p44/p42, p38, and SAPK/JNK MAPKs ${ }^{[17]}$. Moreover, HMGB1 also acts as a DNA-binding cytokine, which can activate downstream immune responses or facilitate tumorigenesis by inducing inflammation ${ }^{[4,18-20]}$. For example, it has been reported that enzalutamide-induced HMGB1 expression facilitates tumor-associated macrophage recruitment and polarization and drives neuroendocrine differentiation via $\beta$-catenin stabilization, indicating that HMGB1 may serve as a new treatment for enzalutamide resistance in patients with advanced or metastatic $\mathrm{PCa}^{[21]}$.

There is evidence that the HMGB1/RAGE axis is involved in inflammation-induced carcinogenesis ${ }^{[22]}$. RAGE, which belongs to the immunoglobulin superfamily, is a cell surface molecule and multi-ligand transmembranous receptor ${ }^{[23]}$. HMGB1 is one of its ligand, and it has been reported to bind RAGE and subsequently activate the mitogen-activated protein kinases in a variety of malignancies, such as colorectal, pancreatic, breast, and oral squamous cell cancer ${ }^{[24-28]}$. Recent publications show that targeting RAGE reduced the level of PSA, the downstream target gene of androgen receptor $(\mathrm{AR})^{[29]}$, indicating that RAGE may play a pivotal role in the regulation of AR in PCa cells. Furthermore, Zhou et al ${ }^{[30]}$ reported that the HMGB1/TLR4-RAGE/sCLU pathway leads to chemoresistance in human prostate tumor cells by triggering the process of cell death, thus providing a survival advantage to residual viable tumor cells. 
Although the upregulation of HMGB1 has been found in several cancers, its role in PCa remains elusive. In addition, our previous study revealed that both HMGB1 and RAGE are highly expressed in PCa tissues and serve as predictive factors for the poor prognosis of PCa patients ${ }^{[31]}$. Moreover, we also clarified that the HMGB1/BRG1 interaction was associated with the activation of Akt function, resulting in proliferation and metastasis of $\mathrm{PCa}^{[32]}$. These results suggest that HMGB1 might be a new prognostic biomarker and therapeutic target for PCa. Here, we summarize the recently published literature to highlight and speculate on the interactions of HMGB1 and RAGE in PCa progression and the possible strategies for the targeted therapy of PCa.

\section{HMGB1 AND RAGE IN THE PROGNOSTIC PREDICTION OF PCA}

HMGB1 is reported to be frequently increased in various types of cancer ${ }^{[33-35]}$. Similarly, HMGB1 is also identified to be upregulated in $\mathrm{PCa}^{[3,36]}$. Intriguingly, androgen deprivation caused the secretion of HMGB1 in prostatic stromal cells, which was considered to be correlated with metastatic $\mathrm{PCA}^{\left[{ }^{[37]}\right.}$. These results support the notion that hormone resistance or metastasis of PCa may be due to androgen deprivation therapy, ultimately increasing the level of HMGB1. Furthermore, He et al. ${ }^{[38]}$ showed in the transgenic adenocarcinoma mouse prostate (TRAMP) model that HMGB1 facilitates the invasion of cancer, and HMGB1 released in serum during cancer progression is associated with severity of clinical pathology.

Overexpression of RAGE and HMGB1 has been observed in PCa. Ishiguro et al. ${ }^{[36]}$ found that the mRNA expression of HMGB1 and its cognate receptor, RAGE, is remarkably higher in primary PCa tissues and hormone-refractory tissues than normal prostate tissues. Kuniyasu et al ${ }^{[37]}$ described that amphoterin is the major product of the HMGB1 gene co-expression with RAGE and functions as a promoting factor in metastatic PCa. Further, Li et al. ${ }^{[39]}$ explored the relationship of HMGB1 expression with the clinicopathological parameters and overall survival of PCa. They also showed that HMGB1 expression is associated with clinical stage (pT), Gleason grade, PSA level, biochemical recurrence, and poor overall survival. Moreover, they revealed that three PCa cells (PC-3, DU145, and LNCaP) had upregulated HMGB1 mRNA and protein compared to non-transformed immortalized prostate cell RWPE-1. Likewise, our previously study highlights and adds to the theme of HMGB1 acting as a biomarker for advanced stages and poor prognosis for $\mathrm{PCa}^{[31,32]}$. All these preclinical and clinical studies greatly exhibited that HMGB1 may play a crucial role in the progression of PCa. In addition, research in other laboratories has also shown that members of HMGB1 are consistently increased in different types of human malignancies, including renal cell carcinoma ${ }^{[33]}$, bladder cancer ${ }^{[40]}$, hepatocellular carcinoma ${ }^{[19]}$, gastric cancer ${ }^{[41]}$, colorectal cancer ${ }^{[42]}$, breast cancer $^{[43]}$, and lung cancer ${ }^{[44]}$. Thus, it would be interesting to survey tumor samples to further examine the incidence of the abnormal expression of HMGB1 and RAGE in other types of tumors. This systematic analysis would be helpful to determine whether HMGB1 can serve as a reliable biomarker for prostate or other type of cancers.

\section{HMGB1 AND RAGE INTERACTING IN PCA}

Growing evidence shows that chronic inflammation is one of the etiological factors of $\mathrm{PCa}^{[45-48]}$. The HMGB1/RAGE inflammatory pathway promotes growth of tumor cells ${ }^{[49]}$. The interactions of HMGB1 and RAGE have been implicated in various types of cancer including $\mathrm{PCa}^{[30]}$. Zhou et al ${ }^{\left[{ }^{[30]}\right.}$ showed that the HMGB1/TLR-4/RAGE pathway promotes cell survival via sCLU induction in human prostate tumor cells. However, the specific roles of HMGB1 in PCa are related to its different locations. It has been reported that extracellular HMGB1 has an entirely different role, functioning as one of the damage-associated molecular patterns or alarmin to activate the innate immune system either alone or in conjunction with cytokines or bound $\mathrm{DNA}^{[50]}$. In the extracellular environment, RAGE binds a downstream domain of HMGB1 at residues 150-183, which regulates chemotaxis, growth, and differentiation in epithelial cells ${ }^{\left[{ }^{[1]}\right]}$. HMGB1 combines 
with RAGE receptor in PCa cells, and blockade of the RAGE/HMGB1 interaction may suppress tumor proliferation ${ }^{[52]}$. This notion is also validated by our recent works ${ }^{[53]}$, which revealed that the depletion of RAGE by siRNA attenuated the proliferation of PCa cells. Our previous study demonstrated that both RAGE and HMGB1 are co-expressed in PCa specimens, indicating that they may have a cooperative role in the development of $\mathrm{PCa}^{[31]}$. More recently, Shetty et al. ${ }^{[54]}$ documented that HMGB1 is one of the target proinflammatory genes for 18 $\alpha$-glycyrrhetinic acid in PCa cells. Hence, a potential mechanism of HMGB1 in promoting the multistep process of PCa development may be associated with the activation of inflammation, and RNAi-based approaches targeting HMGB1/RAGE may act as a novel therapy for PCa.

Most deaths in PCa patients are attributed to the transactivation of AR, which is required for PCa survival and progression ${ }^{[5,56]}$. Recent emerging evidence points out that HMGB1 can transactivate the sex steroid hormone receptors including AR, mineralocorticoid receptor, progesterone receptor, and glucocorticoid receptor ${ }^{[57,58]}$. The transactivation of AR by HMGB1 in PCa may have clinical significance ${ }^{[37]}$. AR activation suggests it has an action on endocrine glands responding to androgen stimulation. Moreover, AR activation is also known to have a crucial role in the progression of androgen-independent $\mathrm{PCa}^{[59]}$. The activation of $\mathrm{AR}$ is regulated by various signaling pathways ${ }^{[60]}$. Thus, these studies indicate that HMGB1 may mediate AR by either acting as co-activator of AR or binding to RAGE in prostate oncogenesis [Figure 1A].

\section{HMGB1 A POTENTIAL TARGET FOR PCA TREATMENT}

HMGB1 is implicated as a late mediator for various human diseases including atherosclerosis, sepsis, inflammation, and arthritis ${ }^{[1,61-63]}$. Much evidence shows that HMGB1 can also act as a therapeutic target for various tumor types including $\mathrm{PCa}^{[64]}$. Furthermore, multiple HMGB1 functions have been identified in different types of tumors, including limitless proliferation potential, escape of apoptosis, angiogenesis, inflammatory microenvironment, and tumor invasion and metastasis. Moreover, HMGB1 has been recently shown to regulate most of the key cell signaling pathways, including NF-кB, p38, JNK, and p44/42 MAPKs, which can be triggered by interacting with RAGE and result in cancer progression and metastasis ${ }^{[4,65,66]}$. Hence, identification of the potential HMGB1 targeting strategies is of functional significance in inhibiting the tumorigenesis of PCa.

Antisense and RNA interference (RNAi) techniques are the most used strategies to silence the expression of target genes ${ }^{[67]}$. Gnanasekar et al. ${ }^{[52]}$ demonstrated that silencing of HMGB1 by RNAi significantly suppressed cell growth and decreased the number of cells undergoing apoptosis. Furthermore, they also suggested that targeting RAGE by RNAi inhibited HMGB1-mediated cell proliferation of PCa cells and reduced the secretion of $\mathrm{HMGB}^{[52]}$. Moreover, Kang et al. ${ }^{[49]}$ demonstrated that knockdown of RAGE or suppression of HMGB1 release by RNAi diminished ATP production and decreased tumor growth in vitro and in vivo. This growth inhibition phenomenon was also demonstrated in androgen-dependent and independent $\mathrm{PCa}$ in xenograft nude mice. In this case, the RNAi strategies that targeted HMGB1 might be a desirable approach to reach therapeutic effects against PCa.

Antibody-based treatment is a promising strategy for targeted cancer therapy. For instance, anti-PD1 antibody treatment has yielded encouraging results in clinical trials ${ }^{[68]}$. In addition, VEGF mAb therapy targeting the angiogenesis process of tumor growth has also been applied ${ }^{[69]}$. Thus, HMGB1 may be a promising therapeutic target for $\mathrm{PCa}$, as it is implicated in cell proliferation, apoptosis regulation, angiogenesis, and metastases ${ }^{[6,70]}$. He et al. ${ }^{[38]}$ found that administration of anti-HMGB1 dramatically suppressed the prostate tumor growth in TRAMP mouse model. The potential inhibition effect of colon cancer development by anti-HMGB1 has also been reported ${ }^{[71]}$. More recently, it was revealed that treatment with anti-HMGB1 neutralizing antibody prevented angiogenesis in colon cancer ${ }^{[72]}$. Furthermore, targeting 
A

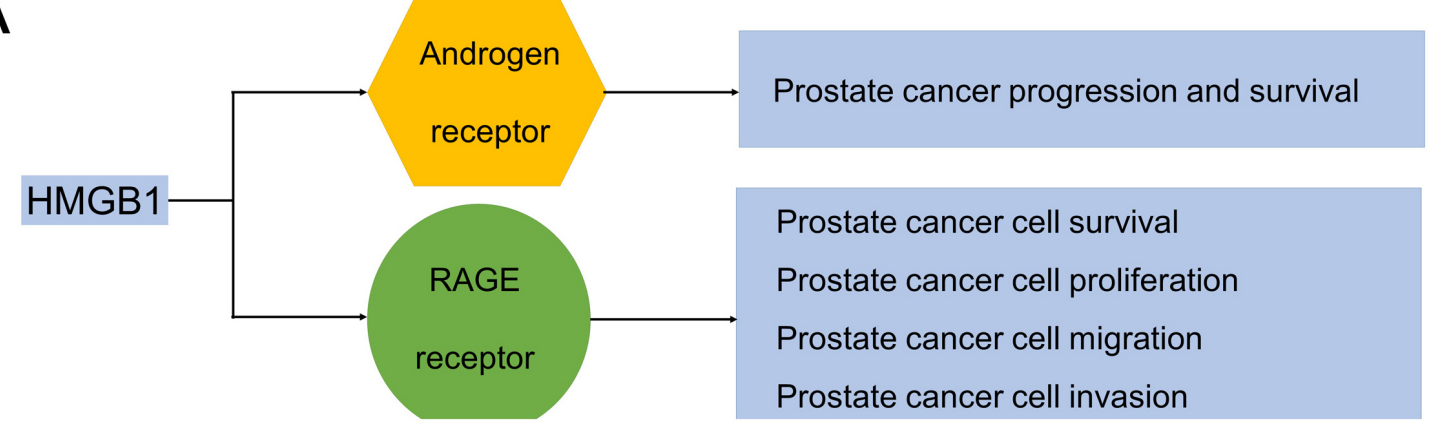

B

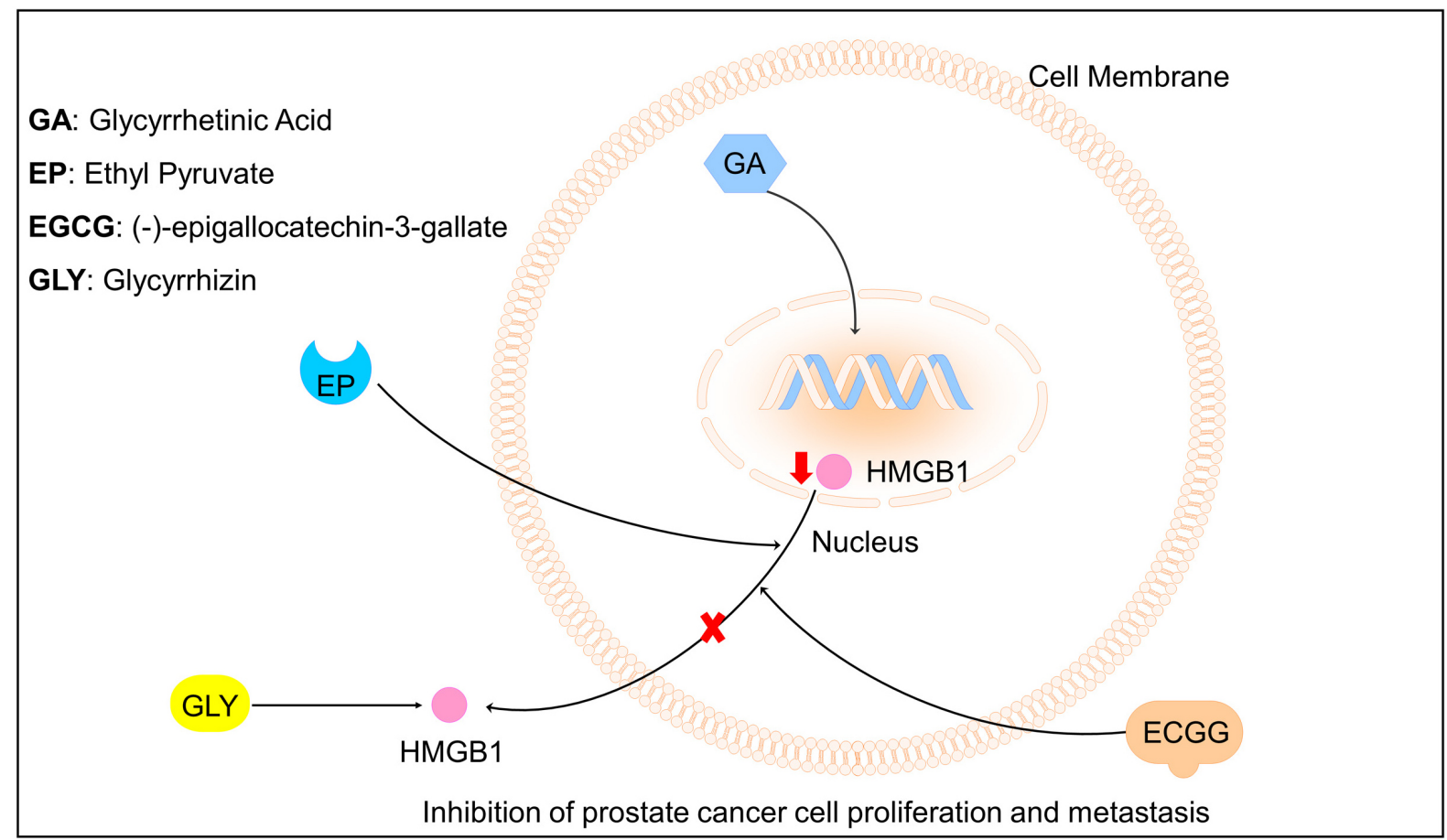

Figure 1. (A) Cellular outcome of HMGB1 interactions with receptors. (B) Hypothetical mode of action of HMGB1 inhibitors.

HMGB1 by antibody was also confirmed to effectively suppress the tumor progression in malignant mesothelioma in vitro and in vivo ${ }^{[73]}$. In summary, these studies proved the curative utility of anti-HMGB1 antibody for cancer treatment generally, which may also be applied for PCa treatment.

The utilization of naturally occurring compounds such as glycyrrhizin, glycyrrhetinic acid, ethyl pyruvate, and green tea phenols, especially (-)-epigallocatechin-3-gallate [Figure 1B], may be another promising approach for HMGB1 targeted therapy, as all of these products have been proved to work against HMGB1 in various cell/disease models ${ }^{[5,74,75]}$. Specifically, Shetty et al. ${ }^{[54]}$ demonstrated that 18 -alpha glycyrrhetinic acid, a derivative of glycyrrhizin that is sufficiently expressed in the licorice root, can reduce the expression of HMGB1 and lead to the curative effects in PCa cells. Other natural compounds known to target HMGB1 include some cholinergic agonists ${ }^{[76]}$, thrombomodulin ${ }^{[77]}$, and low molecular-weight heparin ${ }^{[78]}$. All these natural agents could be tested in PCa patients who show high levels of HMGB1. 
Furthermore, the targeting HMGB1 in clinical trials has been carried out vigorously. Several clinical studies have shown that HMGB1 is a promising biomarker for a variety of cancer types. For example, HMGB1 was reported to link hepatocyte injury to ductular reactions, hepatocyte metaplasia, and hepatocarcinogenesis ${ }^{[79]}$. The release of HMGB1 in response to proapoptotic glioma killing strategies exhibited high efficacy and safety profile because its blockade with glycyrrhizin completely blocked tumor regression ${ }^{[80]}$. These clinical trials could lead to exploring potential cure strategies for cancers harboring high levels of HMGB1 expression including PCa.

\section{CONCLUSION}

From recent studies, evidence on the prominent functions of HMGB1 in the development of cancer is rapidly accumulating. Studies from others and our group indicate that HMGB1 may also play a crucial role in PCa progression. The interaction of HMGB1 with RAGE indicates a central role of HMGB1 in PCa progression. Preclinical studies also support that HMGB1 is upregulated in PCa patients and potentially acts as a novel prognostic biomarker for overall survival of PCa patients. Importantly, identification of the molecules that control the status of HMGB1 would both add to the understanding of the regulation role of HMGB1 and potentially provide additional targeted approaches for the therapeutic manipulation of HMGB1, which may ultimately lead to the improvement of effective therapy for PCa patients. In addition, combining hormonal therapy with agents which target HMGB1 may provide novel avenues for therapeutic development against PCa. Nevertheless, further advanced analysis of HMGB1 and elucidation of the complicacy of the intracellular and extracellular roles of HMGB1 will give us with the knowledge to further improve the development of effective HMGB1-related anti-cancer therapies. Being easily accessible from body serum, HMGB1 has great potential to become a promising and viable tool for early diagnosis and targeted therapy of cancer.

\section{DECLARATIONS}

\section{Authors' contributions}

The author contributed solely to the article.

\section{Availability of data and materials}

Not applicable.

\section{Financial support and sponsorship}

None.

\section{Conflicts of interest}

The author declared that there are no conflicts of interest.

\section{Ethical approval and consent to participate}

Not applicable.

\section{Consent for publication}

Not applicable.

\section{Copyright}

(c) The Author(s) 2021. 


\section{REFERENCES}

1. Sung H, Ferlay J, Siegel RL, et al. Global cancer statistics 2020: globocan estimates of incidence and mortality worldwide for 36 cancers in 185 countries. CA Cancer J Clin 2021;71:209-49. DOI PubMed

2. Center MM, Jemal A, Lortet-Tieulent J, et al. International variation in prostate cancer incidence and mortality rates. Eur Urol 2012;61:1079-92. DOI PubMed

3. Bianchi ME, Beltrame M. Upwardly mobile proteins. Workshop: the role of HMG proteins in chromatin structure, gene expression and neoplasia. EMBO Rep 2000;1:109-14. DOI PubMed PMC

4. Czura CJ, Wang H, Tracey KJ. Dual roles for HMGB1: DNA binding and cytokine. J Endotoxin Res 2001;7:315-21. DOI PubMed

5. Ellerman JE, Brown CK, de Vera M, et al. Masquerader: high mobility group box-1 and cancer. Clin Cancer Res 2007;13:2836-48. DOI PubMed

6. Stros M. HMGB proteins: interactions with DNA and chromatin. Biochim Biophys Acta 2010;1799:101-13. DOI PubMed

7. Lotze MT, Tracey KJ. High-mobility group box 1 protein (HMGB1): nuclear weapon in the immune arsenal. Nat Rev Immunol 2005;5:331-42. DOI PubMed

8. Ueda T, Yoshida M. HMGB proteins and transcriptional regulation. Biochim Biophys Acta 2010;1799:114-8. DOI PubMed

9. Agresti A, Lupo R, Bianchi ME, Muller S. HMGB1 interacts differentially with members of the Rel family of transcription factors. Biochem Biophys Res Commun 2003;302:421-6. DOI PubMed

10. Štros M, Kučírek M, Sani SA, Polanská E. HMGB1-mediated DNA bending: Distinct roles in increasing p53 binding to DNA and the transactivation of p53-responsive gene promoters. Biochim Biophys Acta Gene Regul Mech 2018;1861:200-10. DOI PubMed

11. Das D, Scovell WM. The binding interaction of HMG-1 with the TATA-binding protein/TATA complex. J Biol Chem 2001;276:32597-605. DOI PubMed

12. Amato J, Cerofolini L, Brancaccio D, et al. Insights into telomeric G-quadruplex DNA recognition by HMGB1 protein. Nucleic Acids Res 2019;47:9950-66. DOI PubMed PMC

13. Shen X, Li WQ. High-mobility group box 1 protein and its role in severe acute pancreatitis. World J Gastroenterol 2015;21:1424-35. DOI PubMed PMC

14. Bianchi ME, Agresti A. HMG proteins: dynamic players in gene regulation and differentiation. Curr Opin Genet Dev 2005;15:496506. DOI PubMed

15. Srinivasan M, Banerjee S, Palmer A, et al. HMGB1 in hormone-related cancer: a potential therapeutic target. Horm Cancer 2014;5:127-39. DOI PubMed

16. Sims GP, Rowe DC, Rietdijk ST, Herbst R, Coyle AJ. HMGB1 and RAGE in inflammation and cancer. Annu Rev Immunol 2010;28:367-88. DOI PubMed

17. He C, Sun S, Zhang Y, Xie F, Li S. The role of irreversible electroporation in promoting M1 macrophage polarization via regulating the HMGB1-RAGE-MAPK axis in pancreatic cancer. Oncoimmunology 2021;10:1897295. DOI PubMed PMC

18. Sharma A, Ray R, Rajeswari MR. Overexpression of high mobility group (HMG) B1 and B2 proteins directly correlates with the progression of squamous cell carcinoma in skin. Cancer Invest 2008;26:843-51. DOI PubMed

19. Yan HX, Wu HP, Zhang HL, et al. p53 promotes inflammation-associated hepatocarcinogenesis by inducing HMGB1 release. $J$ Hepatol 2013;59:762-8. DOI PubMed PMC

20. Maeda S, Hikiba Y, Shibata W, et al. Essential roles of high-mobility group box 1 in the development of murine colitis and colitisassociated cancer. Biochem Biophys Res Commun 2007;360:394-400. DOI PubMed

21. Wang C, Peng G, Huang H, et al. Blocking the feedback loop between neuroendocrine differentiation and macrophages improves the therapeutic effects of enzalutamide (MDV3100) on prostate cancer. Clin Cancer Res 2018;24:708-23. DOI PubMed

22. Rojas A, Delgado-López F, Perez-Castro R, et al. HMGB1 enhances the protumoral activities of M2 macrophages by a RAGEdependent mechanism. Tumour Biol 2016;37:3321-9. DOI PubMed

23. Neeper M, Schmidt AM, Brett J, et al. Cloning and expression of a cell surface receptor for advanced glycosylation end products of proteins. J Biol Chem 1992;267:14998-5004. PubMed

24. Mercado-Pimentel ME, Onyeagucha BC, Li Q, Pimentel AC, Jandova J, Nelson MA. The S100P/RAGE signaling pathway regulates expression of microRNA-21 in colon cancer cells. FEBS Lett 2015;589:2388-93. DOI PubMed PMC

25. Kang R, Hou W, Zhang Q, et al. RAGE is essential for oncogenic KRAS-mediated hypoxic signaling in pancreatic cancer. Cell Death Dis 2014;5:e1480. DOI PubMed PMC

26. Kwak T, Drews-Elger K, Ergonul A, et al. Targeting of RAGE-ligand signaling impairs breast cancer cell invasion and metastasis. Oncogene 2017;36:1559-72. DOI PubMed

27. Sasahira T, Kirita T, Bhawal UK, et al. Receptor for advanced glycation end products (RAGE) is important in the prediction of recurrence in human oral squamous cell carcinoma. Histopathology 2007;51:166-72. DOI PubMed

28. Zill H, Günther R, Erbersdobler HF, Fölsch UR, Faist V. RAGE expression and AGE-induced MAP kinase activation in Caco-2 cells. Biochem Biophys Res Commun 2001;288:1108-11. DOI PubMed

29. Elangovan I, Thirugnanam S, Chen A, et al. Targeting receptor for advanced glycation end products (RAGE) expression induces apoptosis and inhibits prostate tumor growth. Biochem Biophys Res Commun 2012;417:1133-8. DOI PubMed

30. Zhou J, Chen X, Gilvary DL, et al. HMGB1 induction of clusterin creates a chemoresistant niche in human prostate tumor cells. Sci Rep 2015;5:15085. DOI PubMed PMC

31. Zhao CB, Bao JM, Lu YJ, Zhao T, Zhou XH, Zheng DY, Zhao SC. Co-expression of RAGE and HMGB1 is associated with cancer progression and poor patient outcome of prostate cancer. Am J Cancer Res 2014;4:369-77. PubMed PMC 
32. Lv DJ, Song XL, Huang B, et al. HMGB1 promotes prostate cancer development and metastasis by interacting with brahma-related gene 1 and activating the Akt signaling pathway. Theranostics 2019;9:5166-82. DOI PubMed PMC

33. Lin L, Zhong K, Sun Z, Wu G, Ding G. Receptor for advanced glycation end products (RAGE) partially mediates HMGB1-ERKs activation in clear cell renal cell carcinoma. J Cancer Res Clin Oncol 2012;138:11-22. DOI PubMed

34. Jiang W, Wang Z, Li X, Fan X, Duan Y. High-mobility group box 1 is associated with clinicopathologic features in patients with hepatocellular carcinoma. Pathol Oncol Res 2012;18:293-8. DOI PubMed

35. Yao X, Zhao G, Yang H, Hong X, Bie L, Liu G. Overexpression of high-mobility group box 1 correlates with tumor progression and poor prognosis in human colorectal carcinoma. J Cancer Res Clin Oncol 2010;136:677-84. DOI PubMed

36. Ishiguro H, Nakaigawa N, Miyoshi Y, Fujinami K, Kubota Y, Uemura H. Receptor for advanced glycation end products (RAGE) and its ligand, amphoterin are overexpressed and associated with prostate cancer development. Prostate 2005;64:92-100. DOI PubMed

37. Kuniyasu H, Chihara Y, Kondo H, Ohmori H, Ukai R. Amphoterin induction in prostatic stromal cells by androgen deprivation is associated with metastatic prostate cancer. Oncol Rep 2003;10:1863-8. PubMed

38. He Y, Zha J, Wang Y, Liu W, Yang X, Yu P. Tissue damage-associated "danger signals" influence T-cell responses that promote the progression of preneoplasia to cancer. Cancer Res 2013;73:629-39. DOI PubMed

39. Li T, Gui Y, Yuan T, et al. Overexpression of high mobility group box 1 with poor prognosis in patients after radical prostatectomy. BJU Int 2012;110:E1125-30. DOI PubMed

40. Huang Z, Zhong Z, Zhang L, et al. Down-regulation of HMGB1 expression by shRNA constructs inhibits the bioactivity of urothelial carcinoma cell lines via the NF-kB pathway. Sci Rep 2015;5:12807. DOI PubMed PMC

41. Kishi S, Nishiguchi Y, Honoki K, et al. Role of glycated high mobility group box-1 in gastric cancer. Int J Mol Sci 2021;22:5185. DOI PubMed PMC

42. Li Y, He J, Zhong D, Li J, Liang H. High-mobility group box 1 protein activating nuclear factor- $\mathrm{kB}$ to upregulate vascular endothelial growth factor $\mathrm{C}$ is involved in lymphangiogenesis and lymphatic node metastasis in colon cancer. J Int Med Res 2015;43:494-505. DOI PubMed

43. Dhumale SS, Waghela BN, Pathak C. Quercetin protects necrotic insult and promotes apoptosis by attenuating the expression of RAGE and its ligand HMGB1 in human breast adenocarcinoma cells. IUBMB Life 2015;67:361-73. DOI PubMed

44. Su Z, Wang T, Zhu H, et al. HMGB1 modulates Lewis cell autophagy and promotes cell survival via RAGE-HMGB1-Erk1/2 positive feedback during nutrient depletion. Immunobiology 2015;220:539-44. DOI PubMed

45. Zhang Q, Liu S, Parajuli KR, et al. Interleukin-17 promotes prostate cancer via MMP7-induced epithelial-to-mesenchymal transition. Oncogene 2017;36:687-99. DOI PubMed PMC

46. Thapa D, Ghosh R. Chronic inflammatory mediators enhance prostate cancer development and progression. Biochem Pharmacol 2015;94:53-62. DOI PubMed

47. Simons BW, Durham NM, Bruno TC, et al. A human prostatic bacterial isolate alters the prostatic microenvironment and accelerates prostate cancer progression. J Pathol 2015;235:478-89. DOI PubMed PMC

48. Sciarra A, Gentilucci A, Salciccia S, et al. Prognostic value of inflammation in prostate cancer progression and response to therapeutic: a critical review. J Inflamm (Lond) 2016;13:35. DOI PubMed PMC

49. Kang R, Tang D, Schapiro NE, et al. The HMGB1/RAGE inflammatory pathway promotes pancreatic tumor growth by regulating mitochondrial bioenergetics. Oncogene 2014;33:567-77. DOI PubMed PMC

50. Tian J, Avalos AM, Mao SY, et al. Toll-like receptor 9-dependent activation by DNA-containing immune complexes is mediated by HMGB1 and RAGE. Nat Immunol 2007;8:487-96. DOI PubMed

51. Huttunen HJ, Fages C, Kuja-Panula J, Ridley AJ, Rauvala H. Receptor for advanced glycation end products-binding COOH-terminal motif of amphoterin inhibits invasive migration and metastasis. Cancer Res 2002;62:4805-11. PubMed

52. Gnanasekar M, Thirugnanam S, Ramaswamy K. Short hairpin RNA (shRNA) constructs targeting high mobility group box-1 (HMGB1) expression leads to inhibition of prostate cancer cell survival and apoptosis. Int J Oncol 2009;34:425-31. PubMed

53. Bao JM, He MY, Liu YW, et al. AGE/RAGE/Akt pathway contributes to prostate cancer cell proliferation by promoting Rb phosphorylation and degradation. Am J Cancer Res 2015;5:1741-50. PubMed PMC

54. Shetty AV, Thirugnanam S, Dakshinamoorthy G, et al. 18 $\alpha$-glycyrrhetinic acid targets prostate cancer cells by down-regulating inflammation-related genes. Int J Oncol 2011;39:635-40. DOI PubMed

55. Liu J, Jiang G, Yang A, Yang G, Yang W, Fang Y. Molecular mechanism of prostate cancer cell apoptosis induced by busulfan via adjustment of androgen receptor phosphatization. Am J Transl Res 2016;8:4881-91. PubMed PMC

56. Patek S, Willder J, Heng J, et al. Androgen receptor phosphorylation status at serine 578 predicts poor outcome in prostate cancer patients. Oncotarget 2017;8:4875-87. DOI PubMed PMC

57. Verrijdt G, Haelens A, Schoenmakers E, Rombauts W, Claessens F. Comparative analysis of the influence of the high-mobility group box 1 protein on DNA binding and transcriptional activation by the androgen, glucocorticoid, progesterone and mineralocorticoid receptors. Biochem J 2002;361:97-103. DOI PubMed PMC

58. Boonyaratanakornkit V, Melvin V, Prendergast P, et al. High-mobility group chromatin proteins 1 and 2 functionally interact with steroid hormone receptors to enhance their DNA binding in vitro and transcriptional activity in mammalian cells. Mol Cell Biol 1998;18:4471-87. DOI PubMed PMC

59. Henzler C, Li Y, Yang R, et al. Truncation and constitutive activation of the androgen receptor by diverse genomic rearrangements in prostate cancer. Nat Commun 2016;7:13668. DOI PubMed PMC

60. Reebye V, Frilling A, Habib NA, Mintz PJ. Intracellular adaptor molecules and AR signalling in the tumour microenvironment. Cell Signal 2011;23:1017-21. DOI PubMed 
61. Tsao CF, Huang WT, Liu TT, et al. Expression of high-mobility group box protein 1 in diabetic foot atherogenesis. Genet Mol Res 2015;14:4521-31. DOI PubMed

62. Qiu YW, Chen D, Xu MY, Li ST. Beneficial effects of dantrolene on sepsis-induced diaphragmatic dysfunction are associated with downregulation of high-mobility group box 1 and calpain-caspase-3 proteolytic pathway. J Surg Res 2016;200:637-47. DOI PubMed

63. Xu K, Cai YS, Lu SM, et al. Autophagy induction contributes to the resistance to methotrexate treatment in rheumatoid arthritis fibroblast-like synovial cells through high mobility group box chromosomal protein 1. Arthritis Res Ther 2015;17:374. DOI PubMed PMC

64. Gnanasekar M, Kalyanasundaram R, Zheng G, et al. HMGB1: a promising therapeutic target for prostate cancer. Prostate Cancer 2013;2013:157103. DOI PubMed PMC

65. Wu X, Mi Y, Yang H, Hu A, Zhang Q, Shang C. The activation of HMGB1 as a progression factor on inflammation response in normal human bronchial epithelial cells through RAGE/JNK/NF-kB pathway. Mol Cell Biochem 2013;380:249-57. DOI PubMed

66. He Q, You H, Li XM, Liu TH, Wang P, Wang BE. HMGB1 promotes the synthesis of pro-IL-1 $\beta$ and pro-IL-18 by activation of p38 MAPK and NF-KB through receptors for advanced glycation end-products in macrophages. Asian Pac J Cancer Prev 2012;13:136570. DOI PubMed

67. Erikson JM, Valente AJ, Mummidi S, et al. Targeting TRAF3IP2 by genetic and interventional approaches inhibits ischemia/reperfusion-induced myocardial injury and adverse remodeling. J Biol Chem 2017;292:2345-58. DOI PubMed PMC

68. van Hooren L, Sandin LC, Moskalev I, et al. Local checkpoint inhibition of CTLA-4 as a monotherapy or in combination with antiPD1 prevents the growth of murine bladder cancer. Eur J Immunol 2017;47:385-93. DOI PubMed

69. Deng L, Stafford JH, Liu SC, et al. SDF-1 blockade enhances Anti-VEGF therapy of glioblastoma and can be monitored by MRI. Neoplasia 2017;19:1-7. DOI PubMed PMC

70. Wang X, Xiang L, Li H, et al. The role of HMGB1 signaling pathway in the development and progression of hepatocellular carcinoma: a review. Int J Mol Sci 2015;16:22527-40. DOI PubMed PMC

71. van Beijnum JR, Dings RP, van der Linden E, et al. Gene expression of tumor angiogenesis dissected: specific targeting of colon cancer angiogenic vasculature. Blood 2006;108:2339-48. DOI PubMed

72. Kikuchi H, Yagi H, Hasegawa H, et al. Therapeutic potential of transgenic mesenchymal stem cells engineered to mediate anti-high mobility group box 1 activity: targeting of colon cancer. J Surg Res 2014;190:134-43. DOI PubMed

73. Yang H, Pellegrini L, Napolitano A, et al. Aspirin delays mesothelioma growth by inhibiting HMGB1-mediated tumor progression. Cell Death Dis 2015;6:e1786. DOI PubMed PMC

74. Smolarczyk R, Cichoń T, Matuszczak S, et al. The role of Glycyrrhizin, an inhibitor of HMGB1 protein, in anticancer therapy. Arch Immunol Ther Exp (Warsz) 2012;60:391-9. DOI PubMed

75. Chang HY, Chen SY, Wu CH, Lu CC, Yen GC. Glycyrrhizin attenuates the process of epithelial-to-mesenchymal transition by modulating HMGB1 initiated novel signaling pathway in prostate cancer cells. J Agric Food Chem 2019;67:3323-32. DOI PubMed

76. Li F, Chen Z, Pan Q, et al. The protective effect of PNU-282987, a selective $\alpha 7$ nicotinic acetylcholine receptor agonist, on the hepatic ischemia-reperfusion injury is associated with the inhibition of high-mobility group box 1 protein expression and nuclear factor $\mathrm{kB}$ activation in mice. Shock 2013;39:197-203. DOI PubMed

77. Nakamura Y, Nakano T, Irie K, et al. Recombinant human soluble thrombomodulin ameliorates cerebral ischemic injury through a high-mobility group box 1 inhibitory mechanism without hemorrhagic complications in mice. J Neurol Sci 2016;362:278-82. DOI PubMed

78. Li S, Eisenstadt R, Kumasaka K, et al. Does enoxaparin interfere with HMGB1 signaling after TBI? J Trauma Acute Care Surg 2016;80:381-7; discussion 387-9. DOI PubMed PMC

79. Hernandez C, Huebener P, Pradere JP, Antoine DJ, Friedman RA, Schwabe RF. HMGB1 links chronic liver injury to progenitor responses and hepatocarcinogenesis. J Clin Invest 2018;128:2436-51. DOI PubMed PMC

80. Candolfi M, Yagiz K, Foulad D, et al. Release of HMGB1 in response to proapoptotic glioma killing strategies: efficacy and neurotoxicity. Clin Cancer Res 2009;15:4401-14. DOI PubMed PMC 